
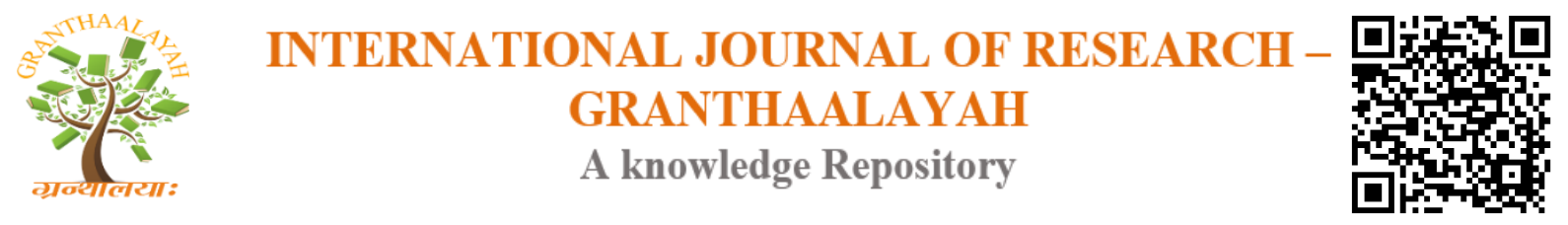

Management

\title{
COMMUNICATION PROBLEMS IN MANAGEMENT
}

\author{
Phillip R. Neely Jr., Ph.D. ${ }^{1}$, Michael Mosley, BA ${ }^{2}$ \\ ${ }^{1}$ Saint Leo University, 3555 Koger Blvd., Duluth, Ga. 30096, USA \\ ${ }^{2}$ Columbia Southern University
}

\begin{abstract}
An array of studies identifies that effective communication is imperative in the workplace to increase employee productivity and organizational performance. Despite the benefits that emerge in the use of effective communication strategies within an organization, many organizations face numerous challenges that emerge in communication breakdowns and disconnects. These challenges affect performance and compromise success. The intent of this paper is to use a mixed method approach that includes a literature review and gathering of primary data from questionnaires and interviews to determine the communication problems in management. The data analysis is achieved through qualitative and quantitative strategies. The study identifies that lack of effective communication is centered on the perceptions that exist within the workforce. Managers perceive that their strategies are effective when in some cases they are not. The study also identifies that tech-assisted communication systems would increase productivity. From these insights, it is imperative that organizations implement changes that will foster effective communication throughout the organization.
\end{abstract}

Keywords: Communication Problems in Management; Communication Strategies; Communication Effectively and Efficiently.

Cite This Article: Phillip R. Neely Jr., and Michael Mosley. (2018). "COMMUNICATION PROBLEMS IN MANAGEMENT." International Journal of Research - Granthaalayah, 6(9), 34-40. https://doi.org/10.5281/zenodo.1435214.

\section{Introduction}

The adoption of working communication strategies is one of the hallmarks of successful management undertakings in the contemporary business environment. Proper communication in the workplace increases productivity and the employees' job satisfaction, hence reduced turnover rates. Additionally, successful communication is useful in creating functional teams, facilitating innovation, ensuring transparency, and helps in building and maintaining healthy relationships amongst employees and the management.

Despite the numerous advantages of proper communication in management, most organizations experience communication breakdown or disconnect, which affects performance. A study carried 
out by Odine (2015) in the United States showed that only 17 percent of the interviewed employees thought that their managers communicated effectively. Insights from the data highlight the disconnect in commutation because the managers taking part in the study indicated that they spent close to 80 percent of their time on issues related to operational communication. Suggestively, the data shows that the efforts that managers put in communication are not commensurate with the achieved results. This realization shows that while managers may think they are communicating effectively, how the information is presented or how it is passed across may affect how employees receive it. Anything that affects the delivery and reception of information to achieve the intended results can be termed as a barrier to communication. With such barriers, employees may not accomplish their duties as expected, which leads to a conflict between the management and the workforce. Consequently, with conflicts, employee productivity and organizational performance are affected and the probability of not achieving the set goals increases.

The significance of this research lies in the intent to provide a better understanding of the barriers that prevent effective communication in managing organizations. The paper will investigate communication problems; the nature of communication systems that companies have put in place and the factors that affect communication between the sender and the recipient. The research will aim to find out what communication issues occur and why they are observed. The paper will also focus on how to overcome these communication issues. The research will be based on a qualitative exploration and discussions while quantitative data will be employed to identify the key problems, their causes, and resolutions. Statistical methods will be used to analyze the collected data. Results will be discussed to draw conclusions based on the available evidence. Recommendations will then be offered on what managers can do to improve communication in the workplace for enhanced performance.

\section{Literature Review}

The subject of communication issues that are faced by managers is discussed by numerous scholars who work in this field because they recognize proper communication as a significant element needed for the ability to maintain successful performance in the contemporary business environment. Managers often pay attention to the influence made on workplace productivity and employee satisfaction because they are critical for positive outcomes. The focus on management is required as these professionals have enough power to affect the personnel, including the interactions with each other and the management and in creating a motivated working environment.

The importance of communication in management teams is recognized by Hedman and Valo (2015), who developed a research study to analyze various challenges that are usually faced during this process. The authors stated that the management is critical for successful business operations because it controls employee performance and ensures that the overall organizational goals are met. In this light, effective communication is a tool that provides an opportunity to influence others within the work environment.

The claims made by Hedman and Valo (2015) are based on the analysis of information obtained from interviews with managers who performed their duties at the international organizations. Seven participants shared their experience and views on communication challenges that were 
experienced in the workplace. Resultantly, the authors categorized problems focusing on conventional and personal objectives, equal and polarized participation, team- and leader-centered communication, consensus and unilateral decision-making, formal and informal communication, as well as, face-to-face and technology-assisted communication. It was established that in the most of cases the management faced problems associated with leadership and decision-making. These issues occurred during meetings when some participants had no opportunity to share their ideas because their ability to speak up was limited by the system or other members.

The authors made their work even more valuable for practice, as they developed a range of recommendations that can be used to maintain effective communication practices. By asking the participants what strategies they preferred to use to overcome such problems, Hedman and Valo (2015) concluded that managers should keep in mind the importance of proper communication for the overall performance and discuss it in the workplace. A respectful environment should be created so that participants of the meetings have a chance to reveal their ideas. In this way, they all had an opportunity to participate in the decision-making process and contribute to constructive outcomes.

Much attention to the issues associated with the communication is evident in a study by Odine (2015). The researcher focused on the problems faced by the management and sought to understand what elements influenced communication in the workplace making it effective or ineffective. The study offers a compressive discussion centered on the attitudes of the senders in the communicative process. Additionally, the effects of using media formats for information sharing are also examined. The role of cultural and gender backgrounds is considered, as well as, the characteristics of the receiver.

From a literature review based on the authoritative sources that reviewed communication problems in managing organizations, Odine (2015) found out that only the identification of these issues in the workplace did not prevent their occurrence. It is significant to implement those strategies that provide an opportunity to avoid those types of communication that affect employee and organizational productivity adversely. Unlike Hedman and Valo (2015) who believed that the discussed problems occurred because of the inability to speak up during meetings, Odine (2015) alludes that the use of improper media and the presence of unclear information was the key shortcoming in the communicative process within organizations. Moreover, the author concluded that many professionals did not pay attention to the characteristics of the receiver of their message (for instance, their background and knowledge). Arguably, Odine (2015) recommended focusing on the receiver when designing messages and engaging in the communication process. The information provided by managers should be precise and easy to comprehend so that the likelihood of confusion is minimized. The media used for communication should not be complicated because different people need to access it. Suggestively, the information should be passed through the most effective media channels and should convey a message that can be understood by any stakeholder within the organization.

Rajhans (2012) also offers critical insights on communication in organizations by focusing on its impact on employee motivation and performance. The research was premised on the notion that effective communication was critical in the workplace because it provided an opportunity to influence the personnel and their willingness to work positively. Additionally, the Rajhans (2012) 
notes that ensuring certain that employee understood the implications of the information communicated correctly enabled managers to contribute to their ability to reach the overall business goals. In this light, there is a consensus between Raijhans (2012) and other researchers that effective flow of information contributed to enhanced employee productivity and organizational performance. By analyzing insights drawn from the literature review and interviews, the researcher managed to identify that the best way to make sure that the recipients understood the message correctly is to encourage them to provide their feedback. Subsequently, the sender can determine if the information sent was used effectively or there were missing links in the application of the information. There is no doubt that there are many benefits that emerge among the workers of they shared their ideas regarding the use of different communication strategies implemented in the organization. With such insights and the feedback gained from the information communicated, the management can enhance the efficiency of the communication process by addressing the shortcomings in the existing processes or by adopting better strategies. Sentiments expressed by Hedman and Valo (2015) are in line with those of Rajhans (2012) who concluded that the cooperation between the management and the personnel has positive influences on the decision-making process. Their collaboration provided additional opportunities to reach organizational goals and business success.

The author emphasized that the participants of communication need to ensure that it is managed as a two-way process to guarantee effectiveness in delivering, receiving, and providing feedback in the communication process. Nevertheless, Odine (2015) and Hedman and Valo (2015) contradict Rajhans (2012) findings that suggest the absence of feedback that follows the instruction as the significant communication issue in management. The researcher emphasizes that, in this situation, employees tend to do what they consider to be right instead of meeting the goals identified by managers.

Zulch (2014) offers fundamental insights in understanding the attributes of a successful communication process. The author focused on the identification of those characteristics that provided managers with an opportunity to develop a successful practice. Much attention was paid to the identification of the leadership style because it affected the way professionals interact with others. The researcher presupposed that being aware of different styles and their characteristics, managers could realize how they affected interaction among employees. Moreover, managers received an opportunity to adapt their leadership so that it benefits their practice. Zulch (2014) encouraged professionals to develop their communication skills because they were significant for appropriate delegation and coordination. While supporting Odine's (2015) perception of the significance of senders' attitudes, Zulch (2014) added that their behavior and personality are also critical to consider. Managers are responsible for the focus on employees' performance on the overall business goals. From these insights, the management should focus on improving communication starting with personnel changes.

The use of people-oriented approach allows making management successful and effective. Given this, professionals should listen to the personnel and provide them with the information that can be easily understood. Employees are to be encouraged to engage in the decision-making initiatives and to share their vision of the discussed issues. Trustful relationships should be used as the basis for successful practice. 
Conrad (2014) believed that business could not be practiced without effectiveness in workplace communication because it ensures that the personnel understand organizational goals and implement practices needed to achieve them. At the same time, communication can be used by managers as a tool of persuasion to ensure employees follow orders and work in the context of the manager's perspective and work according to the provided plan. The author emphasized that not all people can manage communication effectively and efficiently. It is significant to be confident and focused and to provide rational and credible information. Thus, it is possible to claim that Conrad's (2014) views supported Zulch's (2014) ideas regarding the value of managers' characteristics and Odine's (2015) considerations associated with the importance of the quality of information. Conrad (2014) stated that communication skills allow professionals appeal to employees and make them feel respected.

The most significant strength of Conrad's (2014) work is that it includes several case studies. The author identified communication issues that were described in them and provided recommendations considering their improvement. All this information can be employed to enhance practice. Conrad (2014) believed that the major challenges faced by the workers were caused by the limited ability to learn and use effective communication strategies. Resultantly, the author encouraged managers and employees to focus on the development of their skills. Moreover, the researcher identified the use of technology as a possible source of complications associated with the interaction between managers and the personnel, supporting Odine's (2015) ideas. He shared personal views on bad communication practices, but also encouraged them with authoritative sources.

Husain (2013) based his work on the discussion of the significance of maintaining effective communication in the workplace. However, unlike other authors, the researcher focused on the influences made on the organizational changes. Husain (2013) considered that communication between managers and employees affects the willingness of the last ones to perform their duties appropriately. The implementation of changes within a company is often associated with numerous problems, such as increased costs and alteration of practices. Nevertheless, employee resistance is believed to be the most critical issue in this perspective. Effective communication, on the other hand, provides an opportunity to affect the personnel, change their attitudes, and enhance motivation. Supporting the ideas revealed by other authors, Husain (2013) mentioned that it is critical for managers to deliver clear and trustworthy information, as well as, to develop their communication skills. Employees should be able to participate in the decision-making process, and their ideas should be recognized by professionals to feel respected. Only this way successful performance can be achieve.

\section{Research Methodology}

This research uses literature review to collect secondary data to gather information on the subject. The literature review includes scholarly materials such as peer-reviewed journal articles, books, and case studies. It focuses on challenges facing communication in management and also the implications of dysfunctional communication in the workplace. Secondary data about advantages of effective communication in management is also collected in the literature review. 
This research also uses primary data from questionnaires and interviews. This involves workers and managers of an organization. The primary data aim to determine perceptions in management communication. Workers are asked to identify the magnitude to which they feel that their managers communicate effectively. Managers are asked to indicate how they rate themselves regarding effective communication. Management is also asked to indicate the communication channels and strategies that are employed when passing information to employees. Workers are also asked to indicate why they think their managers do not communicate effectively.

\section{Data Analysis and Discussion}

The technique used to analyze qualitative data depends on the method of data collection used. The responses from the participants are represented in the form of charts, and hypothesis test carried out. The qualitative analysis utilizes tools such as measures of dispersion and chi-square method to come up with the conclusion. The tables and charts illustrate the correlation of the parameters chosen.

\section{Rates and Ratios}

The rates or the ratio of the parameter of communication is shown by the fractional portion of the total number of participants. The parameter of communication with highest rate or ration shows that it is one where the workers felt they were important according to their working environment.

\section{Conclusion}

Communication problems in management are caused by lack of adequate ways of determining the efficiency of the communication within the organization. According to the research results, effective communication is dependent on the perceptions of the population (in this case the employees). Most managers assume that they are effective in passing information to their employees. However, the reality is that, according to most employees, their managers are ineffective in passing information. Managers do not realize this since they lack a means of gauging the effectiveness of the communication process. The nature of communication systems put in place by most organizations does not gauge the efficiency of the communication process. From the research results, most employees prefer a tech-assisted communication system. This means supplementing the communication process with technological means of communication such as the use of emails. For example, when a manager informs his/her employees of certain changes in the operations of the organization, the manager could send an email explaining in detail the changes adopted. It is important for managers to use both formal and informal means of communication. Effective communication is key to an organization since it improves productivity.

\section{Recommendations}

Communication is a skill-based aspect. In aiming to improve communication problems in management, managers should, therefore, look to acquire skills that ensure effective communication. Effective communication is usually associated with several skills that help one to adjust their communication depending on the variables being addressed and at a given time. Five many principles help in ensuring the communication skills are effective. First, a manager has to understand himself/herself. Managers are encouraged to be chatty; this makes it appropriate for 
them to start conversations. Second, a manager should understand their audience. This helps using the right language which improves the effectiveness of communication. Listening is also another principle in ensuring effective communication. To convey the right message, a manager must listen to others and understand what the question is or their points of concern. Also, for effective communication, the message should also be simple, concise and straightforward. Finally, the message should be conveyed at the right time in the right place to the right audience. Also, it is important for the management to develop ways to gauge the effectiveness of the communication process. This can be achieved by following up on whatever information was passed. Managers could also pay special attention to feedback from their employees after passing information. This would help the managers to gauge whether their information was interpreted correctly.

\section{References}

[1] Conrad, D. (2014). Workplace communication problems: Inquiries by employees and applicable solutions. Journal of Business Studies Quarterly, 5(4), 105-116.

[2] Creswell, J. W. (2014). Research design: Qualitative, quantitative, and mixed methods approach (4th Ed.). Thousand Oaks, CA: Sage.

[3] Hedman, E., \& Valo, M. (2015). Communication challenges are facing management teams. Leadership \& Organization Development Journal, 36(8), 1012-1024.

[4] Husain, Z. (2013). Effective communication brings successful organizational change. The Business \& Management Review, 3(2), 43-50.

[5] Miles, M. B., Huberman, A. M., Huberman, M. A., \& Huberman, M. (2014). Qualitative data analysis: An expanded sourcebook. Sage.

[6] Odine, M. (2015). Communication problems in management. Journal of Emerging Issues in Economics, Finance, and Banking, 4(2), 1615-1630.

[7] Rajhans, K. (2012). Effective organizational communication: A key to employee motivation and performance. Interscience Management Review, 2(2), 81-86.

[8] Zulch, B. (2014). Leadership communication in project management. Procedia - Social and Behavioral Sciences, 119(2014), 172-181.

*Corresponding author.

E-mail address:phillip.neely@ saintleo.edu/mm357@ bellsouth.net 